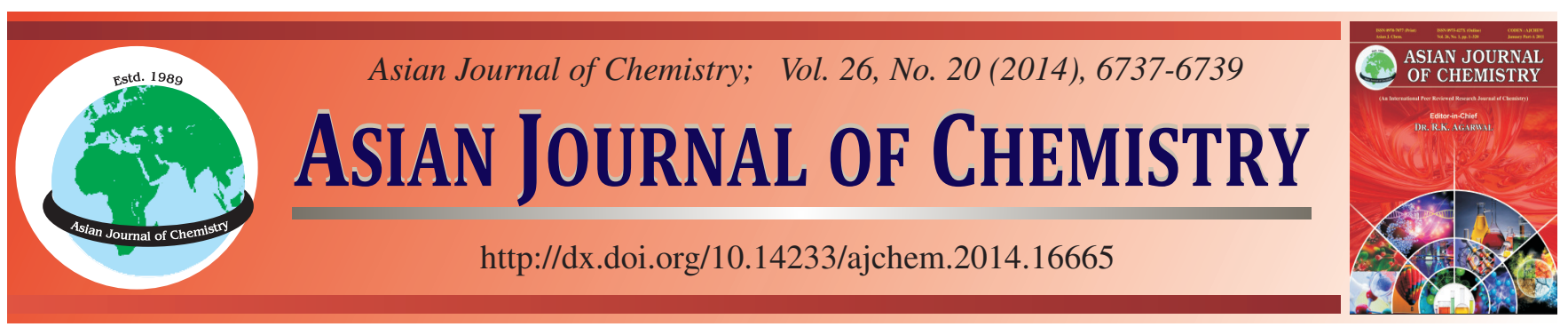

\title{
Characterization of Volatile Constituents from the Flowers and Leaves of Ailanthus altissima by Dynamic Head-Space Collection/GC-MS
}

\author{
YIFAN JIANG $^{1, *}$, JIAYAN YE $^{2}$ and BAO JIANG ${ }^{3}$
}

${ }^{1}$ College of Art, Changzhou University, Changzhou 213164, Jiangsu Prvince, P.R. China

${ }^{2}$ Enzymaker Bioscience Inc, Changzhou 213000, Jiangsu Province, P.R.China

${ }^{3}$ Weinan Vocational \& Technical College, Weinan 714000, Shaanxi Province, P.R. China

*Corresponding author: Tel: +86 13506129207, E-mail: qdjyf@hotmail.com

Received: 9 November 2013;

Accepted: 14 March 2014;

Published online: 25 September 2014;

AJC-16001

Volatile chemicals emitted from the flowers and leaves of Ailanthus altissima were collected using a dynamic headspace technique and identified using gas chromatography-mass spectrometry. The total emission rates of volatile compounds from flowers $(6086.18 \mathrm{ng} / \mathrm{h} / \mathrm{g})$ was about 11.4 folds as in the leaves $(534.68 \mathrm{ng} / \mathrm{h} / \mathrm{g})$. Twenty-four fatty acid derivatives were identified from the flowers accounting for $16.09 \%$ of the total emission rates of volatiles $(979.18 \mathrm{ng} / \mathrm{h} / \mathrm{g})$, while ten fatty acid derivative compounds from the leaves accounting for $87.67 \%$ of the total emission rates of volatiles $(468.74 \mathrm{ng} / \mathrm{h} / \mathrm{g}$ ). The monoterpenoids linalool and (E)-geranial turned out to be the dominant compounds in the flowers accounting for 53.3 and $24.01 \%$ of the total emission rate of volatile compounds repectively. Two Nitrogen-containing compounds were only present in the flowers of A. altissim.

Keywords: Invasive species, Fatty acid derivatives, Linalool, GC-MS, Headspace.

L

\section{INTRODUCTION}

Ailanthus altissima, also known as tree of heaven, is native to northern and central China, Taiwan, Japan and northern Korea $^{1,2}$. After being introduced to United States as the ornamental and medicinal species, its rapid growth and the allelopathic chemicals produced in the roots ${ }^{3}$ which inhibit the growth of the other plants make the tree of heaven a very aggressive and invasive plant able to displace native trees and herb species ${ }^{4}$. Furthermore, the plantlets are capable of regenerating and resprouting vigorously, making its eradication difficult and time consuming.

So to establish successful control program for the exotic A. altissim, it will be important to understand the biology of these plants, especially its reproductive biology. Male flowers of tree of heaven emit a strong foul-smelling odor ${ }^{5}$, which plays a critical role in attracting pollinators for cross-pollination ${ }^{6}$, while the odor from the leaves is sensed mildly and differently by people. It will be interesting to investigate the chemical composition of the volatile from both flowers and leaves to elucidate the correlation of the biosynthesis of the volatiles in different tissues of the same species.

The volatile composition in the leaves of $A$. altissim has been reported by the collection of hydrodistillation and the anaylsis of GC-MS ${ }^{7}$. The aim of this study is to further determine the chemical composition of volatile compounds from the flowers and leaves of A. altissim by head space collection simultaneously to demonstrate the difference of the scent from leaves and flowers.

\begin{tabular}{l} 
EXPERIMENTAL \\
\hline The flowers coupled with the pedicel and the pinnately \\
compound leaf were collected individually from the A. altissim \\
tree of approximately 15 years old grown in the garden of \\
University of Tennessee in May 2010 . \\
Headspace collection: Volatiles emitted from the flowers \\
and leaves of $A$. altissim were collected in an open headspace \\
sampling system (Analytical R pinnately compound leaf \\
research systems, Gainesville, FL, USA). The flowers coupled \\
with the pedicel and the pinnately compound leaf were placed \\
separately in single flasks with about 150 mL distilled water \\
and held in $10 \mathrm{~cm}$ ( 3.9 in) diameter by $30 \mathrm{~cm}$ (11.8 in) tall \\
glass chambers that included a removable O-ring snap lid with \\
an air outlet port. Charcoal-purified air entered the chamber \\
at a flow rate of $0.8 \mathrm{~L} / \mathrm{min}$ from the top through a Teflon hose. \\
Volatiles were collected for $4 \mathrm{~h}$ by pumping air from the \\
chamber through a SuperQ volatile collection trap (Analytical \\
Research Systems, Gainesville, FL, USA) and eluted using \\
100 mL methylene chloride containing 1 -octanal (0.003 \% \\
w/v) as an internal standard.
\end{tabular}


GC-MS analysis: Volatiles collected from flower and leave were analyzed on a Shimadzu 17A gas chromatograph coupled to a Shimadzu QP5050A quadrupole mass selective detector. Separation was performed on a Restek SHR5XLB column $(30 \mathrm{~m} \times 0.25 \mathrm{mmi} . \mathrm{d} . \times 0.25 \mathrm{~mm}$ thickness $)$ under the following conditions: helium was the carrier gas (flow rate of $5 \mathrm{~mL} / \mathrm{min}$ ), a splitless injection (injection injector temperature $250{ }^{\circ} \mathrm{C}$ ) was used and a temperature gradient of $5^{\circ} \mathrm{C} / \mathrm{min}$ from $40^{\circ} \mathrm{C}$ (3-min hold) to $240^{\circ} \mathrm{C}$ was applied. Products were identified using the National Institute of Standards and Technology (NIST) mass spectral database and by comparison of retention times and mass spectra with authentic reference compounds if available. Quantification was performed based on peak areas of mass chromatograms. Representative single-ion peaks of each compound were integrated and compared with the equivalent response of the internal standard (single-ion method).

Statistical analysis: Analyses of volatile quantification in the flowers and leaves in A. altissim were conducted using SAS (Version 8.02; SAS Institute, Cary, NC) based on three biological replicates (volatiles collected from independent flower samples) and two technical replicates (repeat running of a same volatile sample on GC-MS) and SEs were calculated for all mean values.

\section{RESULTS AND DISCUSSION}

The chemical composition and emission rates of the volatile compounds from the flowers and leaves of A. altissim are presented in Table-1. Thirty-six and seventeen compounds were identified from the flowers and leaves respectively, which can be classified into four major classes, including fatty acid derivatives, terpenoids, benzenoids and nitrogen-containing compounds. The total emission rates of volatile compounds from flowers $(6086.18 \mathrm{ng} / \mathrm{h} / \mathrm{g})$ was approximate 11.4 folds as in the leaves $(534.68 \mathrm{ng} / \mathrm{h} / \mathrm{g})$.

The fatty acid derivative is the largest category of volatile compounds in A. altissim both in the flowers and leaves in term of the diversity of the constituents. Twenty-four fatty acid derivative compounds were identified from the flower accounting for $16.09 \%$ of the total emission rates of volatiles (979.18 $\mathrm{ng} / \mathrm{h} / \mathrm{g}$ ). By contrast, eleven fatty acid derivative compounds were detected from the leaves accounting for $87.67 \%$ of the total emission rates of volatiles $(468.74 \mathrm{ng} / \mathrm{h} / \mathrm{g})$, suggesting that the fatty acid derivatives are the dominant compounds both quantitively and qualitively in the leaves. Although six fatty acid derivative volatiles were detected from both flowers and leaves, others showed tissue specificity. (Z)-3-hexen-1-ol acetate is the most abundant compound in the leaves accounting for $61.51 \%$ of the total emission rates of volatile compounds.

Nine terpenoid compounds were identified from the flowers of A. altissim including six monoterpnoids and three sesquiterpenoids accounting for $83.72 \%$ of the total emission rates of volatiles $(5095.44 \mathrm{ng} / \mathrm{h} / \mathrm{g})$, suggesting that terpenoids are the dominant compounds both quantitively and qualitively in the flowers. By contrast, seven terpenoid compounds were detected from the leaves of $A$. altissim including one monoterpnoids and six sesquiterpenoids accounting for $10.93 \%$ of the total emission rates of volatiles $(58.46 \mathrm{ng} / \mathrm{h} / \mathrm{g})$. Although part of the terpenoid volatiles were detected from both leaves and flowers of A. altissim including linalool, germacrene D and Farnesene, others showed tissue specificity. The flowers are more abundant at the monoterpnoids compared to the sesquiterpnoids. The linalool and (E)-geranial account for 53.3 and $24.01 \%$ of the total emission rate of volatile compounds in the flowers, repectively. However, more diverse sesquiterpnoids were identified in the leaves, but the amounts were much lower than the emission rates of monoterpnoids in the flowers.

Only one benzenoid compound, [(Z)-3-Pentenyl]benzene, was identified from both of the leaves and flowers. Two nitrogencontaining compounds, benzyl cyanide and N,N-dibutylformamide, were only present in the flowers with a trace of amount.

In this study, we aimed to investigate the volatile composition from the flowers and leaves of the A. altissim by headspace collection and GC-MS. The volatile composition from the leaves of the A. altissim in this study is not completely consistent with the previous report ${ }^{7}$. Forty-nine compounds were identified by collection of hydrodistillation and the analysis of GC-MS from the fresh leaves of 20 years old A. altissim tree. The main constituents of the volatiles were also classified into fatty acid derivatives $(30.8 \%)$, sesquiterpenoids $(57.4 \%)$, monoterpenoids $(3.6 \%)$ and other compounds $(4.5 \%)$. It indicated that the sesquiterpenoids are the most abundant and dominant volatile compounds from the fresh leaves in the previous study, while the fatty acid derivatives were characterized to be the most abundant volatile compounds from the fresh leaves of 15 years old A. altissim tree in this study. The discrepancy is probably attributed to either the different collection methods or the developmental stage of the samples.

\section{Conclusion}

In this study, thirty-six and seventeen compounds were identified from the flowers and leaves of A. altissim respectively, which can be classified into four major classes, including fatty acid derivatives, terpenoids, benzenoids and nitrogencontaining compounds. The total emission rates of volatile compounds from flowers $(6086.18 \mathrm{ng} / \mathrm{h} / \mathrm{g})$ was about 11.4 folds as in the leaves $(534.68 \mathrm{ng} / \mathrm{h} / \mathrm{g})$. Twenty-four fatty acid derivative compounds were identified from the flowers accounting for $16.09 \%$ of the total emission rates of volatiles $(979.18 \mathrm{ng} / \mathrm{h} / \mathrm{g})$, while ten fatty acid derivative compounds from the leaves accounting for $87.67 \%$ of the total emission rates of volatiles $(468.74 \mathrm{ng} / \mathrm{h} / \mathrm{g})$. Nine terpenoid compounds were identified from the flowers accounting for $83.72 \%$ of the total emission rates of volatiles $(5095.44 \mathrm{ng} / \mathrm{h} / \mathrm{g})$. Six terpenoid compounds were identified from the leaves accounting for $10.93 \%$ of the total emission rates of volatiles $(58.46 \mathrm{ng} / \mathrm{h} / \mathrm{g})$. The monoterpenoids linalool and (E)-geranial turned out to be the dominant compounds in the flowers accounting for 53.3 and $24.01 \%$ of the total emission rate of volatile compounds, repectively.

\section{ACKNOWLEDGEMENTS}

One of the authors, Y.F. Jiang is grateful to the China Scholarship Council for the scholarship support. 


\begin{tabular}{|c|c|c|c|c|}
\hline \multicolumn{5}{|c|}{$\begin{array}{c}\text { TABLE-1 } \\
\text { VOLATILE COMPOSITION AND THEIR EMISSION RATI }\end{array}$} \\
\hline Compounds & $\begin{array}{l}\text { Retention time } \\
(\mathrm{min})\end{array}$ & $\begin{array}{l}\text { Flower } \\
(\mathrm{ng} / \mathrm{h} / \mathrm{g})\end{array}$ & $\begin{array}{c}\text { Leaf } \\
(\mathrm{ng} / \mathrm{h} / \mathrm{g})\end{array}$ & $\begin{array}{l}\text { Method of } \\
\text { identification }\end{array}$ \\
\hline \multicolumn{5}{|l|}{ Fatty acid derivatives } \\
\hline 6-Mthyl-5-hepten-2-one & 8.534 & $5.54 \pm 0.37$ & $16.42 \pm 2.03$ & RT, MS \\
\hline (Z)-3-Hexen-1-ol acetate & 8.93 & $318.19 \pm 46.25$ & $328.87 \pm 29.34$ & RT, MS, AS \\
\hline Nonanal & 12.344 & $9.69 \pm 1.80$ & $18.31 \pm 1.26$ & $\mathrm{RT}, \mathrm{MS}$ \\
\hline 1,3-Dimethylcyclopentanol & 13.801 & $274.46 \pm 38.4$ & - & RT, MS, AS \\
\hline cis-3-Hexenyl iso-butyrate & 14.909 & $74.20 \pm 6.88$ & - & RT, MS \\
\hline 2-Mthyl- 2-Penten-1-ol & 15.162 & $15.73 \pm 1.28$ & - & RT, MS \\
\hline 7-Octen-2-one & 15.271 & $9.13 \pm 1.13$ & - & $\mathrm{RT}, \mathrm{MS}$ \\
\hline Decanal & 15.382 & $19.85 \pm 2.47$ & $16.01 \pm 1.94$ & $\mathrm{RT}, \mathrm{MS}$ \\
\hline (Z)-3-Hexenyl 2-methylbutanoate & 15.718 & $3.03 \pm 0.51$ & - & $\mathrm{RT}, \mathrm{MS}$ \\
\hline 3-Hexen-2-one & 15.971 & $18.27 \pm 1.72$ & - & $\mathrm{RT}, \mathrm{MS}$ \\
\hline (E)-4-Dodecenyl acetate & 17.047 & $144.26 \pm 20.06$ & - & RT, MS, AS \\
\hline (S)-(2E)-3,7-Dimethyloctadiene-1,4-diol & 17.396 & - & $5.02 \pm 0.79$ & $\mathrm{RT}, \mathrm{MS}$ \\
\hline 6-Methyl-7-Octen-2-one & 17.825 & $1.43 \pm 0.22$ & - & RT, MS \\
\hline Cyclohexyl butanoate & 19.967 & $1.13 \pm 0.16$ & - & $\mathrm{RT}, \mathrm{MS}$ \\
\hline 3-Methyl-5-hexen-3-ol & 21.085 & $2.04 \pm 0.3$ & - & $\mathrm{RT}, \mathrm{MS}$ \\
\hline (E)-6,10-Dimethyl-5,9-undecadien-2-one & 21.938 & $19.97 \pm 1.74$ & $63.99 \pm 8.1$ & RT, MS \\
\hline (E)-3-Dodecenyl acetate & 22.465 & $4.88 \pm 0.68$ & - & RT, MS \\
\hline 2,6-Dimethylheptane & 25.122 & - & $0.82 \pm 0.13$ & $\mathrm{RT}, \mathrm{MS}$ \\
\hline 2-Methylpropanoic anhydride & 25.216 & - & $1.42 \pm 0.27$ & RT, MS \\
\hline Tricyclo[3.1.0.0(2,4)]hexane & 25.384 & $36.92 \pm 4.17$ & - & $\mathrm{RT}, \mathrm{MS}$ \\
\hline (E)-3-Tetradecenylacetate & 29.609 & $1.91 \pm 0.29$ & - & RT, MS \\
\hline (Z)-11-Tetradecen-1-ol acetate, & 29.664 & $2.93 \pm 0.24$ & - & $\mathrm{RT}, \mathrm{MS}$ \\
\hline 1-Hexadecanol acetate & 30.085 & $2.21 \pm 0.17$ & - & RT, MS \\
\hline $4,8,12$-Tetradecatrienal-5,9,13-trimethyl & 30.817 & $5.02 \pm 0.65$ & $16.73 \pm 2.62$ & RT, MS \\
\hline (Z)-5-Tetradecen-1-ol acetate & 33.664 & $2.48 \pm 0.31$ & - & RT, MS \\
\hline (E)-7-Dodecen-1-ol acetate & 33.748 & $4.39 \pm 0.6$ & - & RT, MS \\
\hline Decyl acetate & 34.134 & $1.52 \pm 0.13$ & - & $\mathrm{RT}, \mathrm{MS}$ \\
\hline 2-Ethylhexyl acetate & 36.831 & - & $1.15 \pm 0.18$ & RT, MS \\
\hline \multicolumn{5}{|l|}{ Terpenoids } \\
\hline (E)- $\beta$-Ocimene & 10.078 & $86.23 \pm 9.34$ & - & RT, MS, AS \\
\hline Linalool oxide & 11.553 & $90.87 \pm 8.57$ & - & RT, MS \\
\hline Linalool & 12.03 & $3243.89 \pm 402.83$ & $13.61 \pm 0.07$ & RT, MS, AS \\
\hline Ho-trienol & 12.127 & $3.47 \pm 0.47$ & - & RT, MS \\
\hline Epoxylinalol & 14.282 & $32.01 \pm 4.82$ & - & $\mathrm{RT}, \mathrm{MS}$ \\
\hline (E)-Geranial & 17.608 & $1461.03 \pm 152.09$ & - & RT, MS, AS \\
\hline Germacrene A & 20.352 & - & $5.37 \pm 0.71$ & $\mathrm{RT}, \mathrm{MS}$ \\
\hline$\beta$-caryophyllene & 21.072 & - & $21.37 \pm 1.58$ & $\mathrm{RT}, \mathrm{MS}$ \\
\hline$\alpha$-humulene & 22.072 & - & $4.37 \pm 0.82$ & $\mathrm{RT}, \mathrm{MS}$ \\
\hline$\alpha$-Bergamotene & 22.723 & $145.94 \pm 16.33$ & - & RT, MS, AS \\
\hline Germacrene D & 22.841 & $2.08 \pm 0.31$ & $12.92 \pm 0.6$ & RT, MS \\
\hline Farnesene & 23.083 & $29.92 \pm 4.11$ & $0.82 \pm 0.05$ & RT, MS \\
\hline \multicolumn{5}{|l|}{ Benzenoids } \\
\hline [(Z)-3-Pentenyl]benzene & 28.679 & $3.23 \pm 0.52$ & $7.48 \pm 1.04$ & RT, MS \\
\hline \multicolumn{5}{|l|}{ Nitrogen-containing compounds } \\
\hline Benzyl cyanide & 13.982 & $2.39 \pm 0.18$ & - & RT, MS \\
\hline N,N-Dibutyl formamide & 18.491 & $5.94 \pm 0.7$ & - & $\mathrm{RT}, \mathrm{MS}$ \\
\hline Total & & $6086.18 \pm 503.92$ & $534.68 \pm 39.82$ & \\
\hline Fatty acid derivatives & & $979.18 \pm 113.46$ & $468.74 \pm 50.33$ & \\
\hline Terpenoids & & $5095.44 \pm 423.84$ & $58.46 \pm 4.17$ & \\
\hline Benzenoids/Phenylpropanoids & & $3.23 \pm 0.52$ & $7.48 \pm 1.04$ & \\
\hline Nitrogen-containing compounds & & $8.33 \pm 0.74$ & - & \\
\hline
\end{tabular}

\section{REFERENCES}

1. CSIR. Wealth of India (Raw materials), vol-IA (Revised). Publications and information directorate, council of scientific and industrial research, New Delhi, pp.115 (1985).

2. http://www.conserveonline.org/subjects.
3. V. De Feo, L. De Martino, E. Quaranta and C. Pizza, J. Agric. Food Chem., 51, 1177 (2003).

4. G.A. Wright and F.P. Schiestl, Funct. Ecol., 23, 841 (2009).

5. L.B. Knapp and C.D. Canham, J. Torrey Bot. Soc., 127, 307 (2000).

6. P. kundu and S. Laskar, Phytochem. Rev., 9, 379 (2010).

7. J. Mastelic and I. Jerkovic, Croat. Chem. Acta, 75, 189 (2002). 